\title{
Intramuscular vaccination of young calves with a Salmonella Dublin metabolic-drift mutant provides superior protection to oral delivery
}

\author{
Tetsuo Mizuno*, Malcolm McLennan, Darren Trott \\ School of Veterinary Science, The University of Queensland, Brisbane, Queensland, 4072, Australia
}

(Received 5 June 2007; accepted 17 December 2007)

\begin{abstract}
In homologous and heterologous challenge trials using calves $\leq 6$ weeks old, this comparative study investigated safety, in vivo behaviour and protective properties of oral and intramuscular vaccination with recently developed live attenuated Salmonella Dublin mutant N-RM25. Neither oral nor intramuscular vaccination produced unacceptable side effects. However, the vaccine strain was isolated for up to eight days from the faeces of orally vaccinated calves, but not intramuscularly vaccinated calves. Irrespective of the vaccination route, N-RM25 was isolated in low numbers $\left(\leq 1 \times 10^{2} \mathrm{cfu} / \mathrm{g}\right)$ from the liver and spleen of calves euthanized at different time points post-vaccination. Vaccination by either route significantly reduced clinical signs and faecal shedding, prevented the development of systemic infection and protected calves from homologous lethal challenge conducted within 14 days post-immunisation. No challenge strain was isolated from major organs and the gut at 18 days post-challenge (except for a single mesenteric lymph node (MLN) specimen from the intramuscular group, but only following enrichment). Following heterologous challenge with a virulent Salmonella Typhimurium strain at 14 and 20 days post-immunisation, all vaccinated animals exhibited significantly fewer clinical signs and colonisation of the intestinal tract than non-vaccinated controls. When compared to oral vaccination, intramuscular vaccination significantly reduced the frequency of faecal shedding of $S$. Typhimurium $(p=0.0023)$ and markedly reduced colonisation of MLN. The findings indicate that intramuscular administration of N-RM25 was safer in terms of environmental contamination by the vaccine and provided better early onset protection in young calves following both homologous and heterologous challenge.
\end{abstract}

Salmonella Dublin / metabolic-drift mutant / live attenuated vaccine / early onset protection / calf

\section{INTRODUCTION}

Salmonella is an important zoonotic pathogen and causes significant morbidity and mortality in food-producing animals $[3,23,42,46]$. In cattle industries, introduction of modern intensive production and large-scale trading systems have resulted in an increased risk of animals being exposed to a wide range of Salmonella serovars [2, 43, 52], some of which have developed resistance to multiple antimicrobial agents $[31,33]$. To address this, a prophylactic approach to controlling a broad

*Corresponding author: t.mizuno@uq.edu.au spectrum of different Salmonella serovars is desirable. The most common Salmonella serovars isolated from cattle are Salmonella enterica subspecies enterica serovars Dublin ( $S$. Dublin) and Typhimurium $(S$. Typhimurium) $[3,8,15,47]$. $S$. Dublin is a hostadapted bacterium which mainly colonises cattle and often causes systemic infection in calves [34, 49, 52, 54]. Compared with this, $S$. Typhimurium is one of the most common Salmonella serovars isolated from both animals and humans, and often produces enteric salmonellosis [39, 52, 54]. Calves younger than six weeks old are most susceptible to Salmonella infection, peaking at 2-3 weeks for 
$S$. Typhimurium and 4-5 weeks for $S$. Dublin $[52,54]$.

Commercially available vaccines (killed vaccines) produce only modest protection against Salmonella in calves in the most susceptible age group $(\leq 7 \text { weeks of age })^{1}$. Some live vaccine candidates, such as aromaticdependent $\left(\right.$ aro $\left.^{-}\right)$mutants [29, 40] and DNA adenine methylase (Dam) deficient mutants $[12,28]$ of Salmonella, have shown promise in preventing both homologous and heterologous Salmonella infection when orally administered to calves. However, while advanced oral delivery methods, such as encapsulation in microparticles have been developed $[7,14]$, most live attenuated Salmonella vaccines administered to ruminants by this route can still potentially contaminate the environment due to regurgitation [10] and/or faecal shedding [29, 40]. Furthermore, because these vaccine strains are genetically modified organisms (GMO), their use in animal production is not permitted in certain countries due to public health concerns [51].

A new, live attenuated vaccine, N-RM25, was previously created from a virulent wild strain of $S$. Dublin utilising metabolicdrift (spontaneous chromosomal) mutations induced by nalidixic acid and rifampicin followed by selection using new criteria developed based on a new immunity stimulation concept of slow "drip feeding" [27]. N-RM25 was confirmed to be highly stable with no cross-resistance to ten different antimicrobials. Following parenteral vaccination of mice, $\mathrm{N}$ RM25 was also confirmed to be safe and efficacious, inducing both significant serum and mucosal immune responses and protecting against homologous lethal challenge infection [27].

In the present study, calves were vaccinated by oral or intramuscular (IM) route and challenged at less than six weeks of age to confirm the safety of this strain, assess its behaviour in this host and determine its ability to initiate

${ }^{1}$ House J.K., Smith B.P., Evaluation of bovine Salmonella vaccines, in: USAHA (Ed.), Proc. Annual meeting of the United States Animal Health Association, Louisville, KY, USA, 1997.

Page 2 of 16 (page number not for citation purpose) protection against virulent homologous $S$. Dublin and heterologous $S$. Typhimurium challenge strains.

\section{MATERIALS AND METHODS}

\subsection{Bacterial preparation}

The vaccine strain used in this study, N-RM25, was created from $S$. Dublin wild strain FD436 utilising metabolic-drift mutations [27]. FD436 was also used as the challenge strain in the homologous vaccine trial. $S$. Typhimurium wild strain DH436 (the causative organism of a Salmonella outbreak on a dairy farm in Millmerran, Queensland, Australia, in 2003) was used as the challenge strain in the heterologous vaccine trial. In preparing vaccine and challenge strains, each strain was suspended in phosphate-buffered saline solution (PBS) to give approximate concentrations of $10^{7}$ colony forming units $(\mathrm{cfu}) / \mathrm{mL}$. The suspensions were flooded onto reduced sheep blood agar (SBA) plates and the plates anaerobically incubated at $37^{\circ} \mathrm{C}$ for $6 \mathrm{~h}$ (for the wild strains) and $10 \mathrm{~h}$ (for the metabolicdrift mutant). Bacteria growing on each plate were harvested and washed in warm $\left(37^{\circ} \mathrm{C}\right) \mathrm{PBS}$ once for the homologous trial and three times for the heterologous trial. When vaccinating or challenging via the oral route, the bacteria were administered with a buffer solution $\left(1 \mathrm{~g} \mathrm{MgCO}_{3}, 1 \mathrm{~g} 2 \mathrm{MgO}\right.$. $3 \mathrm{SiO}_{2}$, and $1 \mathrm{~g} \mathrm{NaHCO}_{3}$ in $20 \mathrm{~mL}$ distilled water).

\subsection{Experimental animals}

Two-week old Salmonella-negative, male, Friesian calves were obtained after they were prescreened three times on the basis of faecal culture and confirmed to be free of Salmonella infection. The calves were fed two litres of colostrum immediately after birth and at $12 \mathrm{~h}$ and $24 \mathrm{~h}$ of age. Calves which had serum protein concentrations of greater than $50 \mathrm{~g} / \mathrm{L}$ at the first week of age were selected for the trials, as these calves were thought to have received sufficient maternal antibodies via colostrum [45]. Milk replacement formula was then given twice a day (7:00 am and 4:00 pm) and feeding of commercial calf pellets was started once the calves were three weeks old.

\subsection{Study design}

\subsubsection{Homologous vaccine trial}

In the oral vaccine trial, 12 calves were divided into three groups $(n=2$ in the vaccine 
control group, $n=6$ in the vaccine-and-challenge group, $n=4$ in the challenge control group). To minimise the risk of potential contamination of the environment by vaccine organisms, single vaccination was used in this trial. Calves in the vaccine control and the vaccine-and-challenge groups were vaccinated once with a dose of $3.5 \times$ $10^{10} \mathrm{cfu} /$ animal on day 0 . Calves in the vaccineand-challenge and the challenge control groups were then challenged orally on day 14 (14 days post-vaccination (PV)) using FD436 with a dose of $2.7 \times 10^{9} \mathrm{cfu} /$ animal (approximately 100 times greater than its $50 \%$ infectious dose $\left.\left(\mathrm{ID}_{50}\right)\right)$. Two calves in the vaccine-and-challenge group were scheduled for euthanasia on day 18 to examine the distribution and persistence of the vaccine and challenge strains in the host. All surviving calves, except the calves in the vaccine control group, were euthanized on day 32 or upon showing severe clinical signs of salmonellosis. Calves in the vaccine control group were euthanized on day 40.

In the intramuscular (IM) vaccine trial, ten calves were divided into two groups $(n=6$ in the vaccine-and-challenge group, $n=4$ in the challenge control group). Calves in the vaccineand-challenge group were vaccinated in the biceps femoris muscle using N-RM25 with a dose of $4.1 \times$ $10^{8} \mathrm{cfu} /$ animal on day 0 and booster vaccinated $\left(7.2 \times 10^{9} \mathrm{cfu} /\right.$ animal of N-RM25) 13 days PV. One calf from this group was sacrificed on each of days 6 and 18 to investigate the distribution and persistence of the vaccine strain in the host All calves were challenged orally on day 20 using FD436 with a dose of $1.8 \times 10^{9} \mathrm{cfu} /$ animal. Calves were euthanized on day 38 or upon showing severe clinical signs of salmonellosis. Calves were weighed on day -1 (pre-vaccination) and day 16 to investigate the influence of vaccination on their weight.

\subsubsection{Heterologous vaccine trial}

Twenty-one calves were divided into three groups $(n=7$ in the oral vaccine-and-challenge group, $n=7$ in the IM vaccine-and-challenge group, $n=7$ in the challenge control group). Calves in the vaccine-and-challenge groups were vaccinated using $\mathrm{N}-\mathrm{RM} 25$ with a dose of $1 \times$ $10^{9} \mathrm{cfu} /$ animal via the respective routes on day 0 . Booster vaccination was carried out on day 14 with doses of $1 \times 10^{10} \mathrm{cfu} /$ animal for the oral group and $1 \times 10^{9} \mathrm{cfu} /$ animal for the IM group. All calves were then challenged using DH436 twice (at a dose of $1 \times 10^{8} \mathrm{cfu} /$ animal (approximately the same as its $\left.\mathrm{ID}_{50}\right)$ on day 28 , and $1 \times 10^{9} \mathrm{cfu} /$ animal on day 36 ). Euthanasia was conducted for postmortem examination on day 43.

\subsection{Observation of clinical appearance}

Clinical appearance was monitored daily throughout (but twice daily during the ten-day post-challenge (PC) period in the homologous trial). Because $S$. Dublin often produces systemic infection, six parameters - appetite, body temperature, heart rate, respiration, hydration, and general appearance - were examined in the homologous vaccine trial to monitor the occurrence of septicaemic salmonellosis. In the heterologous vaccine trial, the parameters were the same, except that faecal consistency instead of respiration was monitored because $S$. Typhimurium often produces localised infection in the gut. The following clinical signs were classed as abnormal: (1) a drop in appetite to $50 \%$ or less of normal appetite; (2) a rise in rectal temperature to over $40^{\circ} \mathrm{C}$ or a drop of more than one degree centigrade below the average rectal temperature of each calf between day 6 and day 12; (3) an increase in heart rate of more than $30 \%$ of the average heart rate of each calf between day 6 and day 12; (4) an increase in respiration rate of more than $30 \%$ of the average respiration rate of each calf between day 6 and day 12; (5) dehydration of $7 \%$ or more as determined by skinfold test and the presence of enophthalmos [13]; (6) depressed demeanour (as evidenced by a lack of response to external stimuli and unwillingness to move [4]) and/or recumbency and; (7) watery consistency of faeces. In addition to testing positive for Salmonella following blood culture, calves showing clinical signs in four or more of the above six respective parameters for each trial were classed as having septicaemic salmonellosis and immediately euthanized. The study protocol was approved by the Animal Ethics Committees of the University of Queensland and of the Commonwealth Scientific and Industrial Research Organisation, Australia.

\subsection{Sampling of faeces, blood, tissues and intestinal contents}

In both homologous and heterologous trials, faecal specimens from each calf were collected

(page number not for citation purpose) Page 3 of 16 
directly from the rectum every 1-3 days to monitor Salmonella shedding. Blood was aseptically collected from a jugular vein for bacteriology from the day of vaccination for three consecutive days, then every three days thereafter. The same sampling schedule was applied following booster vaccination and challenge infection. Tissues from lung, liver, spleen, kidney, ileocaecal MLN, and gall bladder bile were aseptically collected upon postmortem examinations for bacteriology. Intestinal contents from ileum, caecum, colon, and rectum (rectal contents were collected only in the heterologous trial), were also collected at the same time.

\subsection{Isolation and identification of Salmonella}

Faecal, tissue and intestinal content specimens were cultured for Salmonella using a conventional direct isolation (DI) and identification method [32] with some modifications. Briefly, these specimens were directly inoculated onto xylose lysine deoxycholate (XLD, Oxoid Ltd., Hampshire, England) plates and incubated at $37^{\circ} \mathrm{C}$ for 24 to $48 \mathrm{~h}$. Three colonies suspected of being Salmonella from each XLD plate were transferred to cystine-lactose-electrolyte deficient (CLED, Oxoid) medium. After incubation for 24 to $48 \mathrm{~h}$, colonies suspected of being Salmonella were then tested using Salmonella polyvalent agglutinating serum (Murex Biotech Ltd., Dartford, England). Colonies which produced a positive result were further tested by culturing in lysine decarboxylase (LD, Oxoid) and ONPG broths. Colonies that showed lysine decarboxylation and an absence of $\beta$-D-galactosidase were identified as Salmonella. When Salmonella were not isolated through the DI method, the following enrichment isolation (EI) method was used. One gram of each specimen was added to $10 \mathrm{~mL}$ of mannitol selenite broth (MSB, Oxoid) medium containing $0.0001 \mathrm{~g} \mathrm{~L}$-cystine (BDH, Victoria, Australia), incubated at $37^{\circ} \mathrm{C}$ for $24 \mathrm{~h}$, after which the DI method was repeated.

One millilitre of each blood and bile specimen was directly inoculated into $10 \mathrm{~mL}$ of cooked meat broth medium, incubated at $37^{\circ} \mathrm{C}$ for $48 \mathrm{~h}$ and tested using the DI method. A Muller-Hinton medium (Oxoid) containing $0.04 \%$ nalidixic acid and $0.02 \%$ rifampicin (MHNR) was used to distinguish the vaccine strain (nalidixic acid and rifampicin resistant) from the wild strain (nalidixic acid and rifampicin sensitive). Strains identified as

Page 4 of 16 (page number not for citation purpose)
Salmonella were sent to the Salmonella Reference Laboratory in Queensland Health for serotyping.

For quantitative investigation, one gram of each faecal, tissue and intestinal content specimen was homogenized and mixed with sterile PBS to a total volume of $10 \mathrm{~mL}$. The number of viable Salmonella cells was then determined [25] using XLD plates and MHNR plates. Quantitative culture results of faecal and intestinal content specimens were expressed as $\mathrm{cfu} / \mathrm{g}$ on a dry matter basis.

\subsection{Statistical methods}

The two-tailed Fisher's exact test was used to analyse data in all experiments. Analyses were performed using GraphPad InStat version 3.05 (GraphPad Software, San Diego, USA). Results were considered statistically significant when probability was less than $5 \%(p<0.05)$.

\section{RESULTS}

\subsection{Homologous vaccine trial}

\subsubsection{Clinical appearance}

In both the oral and IM vaccine trials, none of the calves developed clinical signs following vaccination, except soft stools in a few orally vaccinated calves. In the oral trial, one calf in the vaccine-and-challenge group was euthanized on day 8 due to severe signs of pneumonia confirmed to be caused by Pasteurella multocida. In the IM trial, calves in the vaccine-and-challenge group showed transient fever and local inflammatory reactions around the injection site for up to four days following booster vaccination. However, all calves in this group were active with good appetite during this period. There was no significant difference in body weight between the vaccinated and control calves between day -1 and day 16 in the IM vaccine trial.

Following challenge infection, calves in the challenge control group died or were euthanized due to severe clinical signs of salmonellosis by four days PC. By comparison, all vaccinated calves in both the oral and IM vaccine trials developed clinical signs at a significantly lower frequency (total clinical signs during the ten-day observation period 
PC: $p<0.0001$ ) and were protected from lethal challenge infection (oral trial: $p=$ 0.0079, IM trial: $p=0.0286$ ) (Tabs. I and II). The vaccinated calves in both the oral and IM trials developed similar clinical signs, such as high temperature $\left(>40^{\circ} \mathrm{C}\right)$ and profuse watery diarrhoea, sometimes with mucus and blood, for up to nine days following challenge. Some of the calves also appeared depressed for 1-3 days PC and showed increased heart and respiration rates during this period. However, no vaccinated calves lost appetite. In contrast, the challenge control calves in both the oral and IM trials produced more critical signs, such as anorexia, very high fever $\left(>40.5^{\circ} \mathrm{C}\right)$, tachypnea, severe depression and recumbency, but only developed a small amount of diarrhoea sometimes with mucus and blood. Calves in the vaccine control group in the oral trial were healthy throughout the 40-day observation period.

\subsubsection{Isolation of Salmonella from faeces}

In the oral vaccine trial, the vaccine strain N-RM25 was isolated from the vaccinated calves using the DI method for up to two days PV and using the EI method for up to eight days PV. The vaccine strain was never isolated from the calves vaccinated via the IM route throughout the observation period. The difference in the frequency of faecal isolation of the vaccine strain between the oral and IM groups during the pre-challenge period was significant $(p<0.0001)$ (Tab. I).

On the day following challenge infection, approximately $10^{6}-10^{7} \mathrm{cfu} / \mathrm{g}$ of the challenge strain FD436 was isolated from the faeces of

Table I. Oral and intramuscular vaccine trials in calves using N-RM25 followed by homologous challenge infection with a wild strain of Salmonella Dublin, FD436.

\begin{tabular}{|c|c|c|c|c|c|c|c|c|c|}
\hline Trial & Group $^{a}$ & $\begin{array}{c}\text { No. of } \\
\text { calves } \\
\text { challenged }\end{array}$ & $\begin{array}{l}\text { No. of calves } \\
\text { surviving } \\
\text { post- } \\
\text { challenge }\end{array}$ & $\begin{array}{c}\text { Mean } \\
\text { time until } \\
\text { death }^{\mathrm{b}}(\mathrm{h})\end{array}$ & $\begin{array}{l}\text { Protection } \\
(\%)\end{array}$ & $\begin{array}{c}\text { Pre- } \\
\text { challenge } \\
\text { faecal } \\
\text { culturing }\end{array}$ & $\begin{array}{c}\text { Pre- } \\
\text { challenge } \\
\text { blood } \\
\text { culturing }\end{array}$ & $\begin{array}{c}\text { Post- } \\
\text { challenge } \\
\text { faecal } \\
\text { culturing }\end{array}$ & $\begin{array}{c}\text { Post- } \\
\text { challenge } \\
\text { blood } \\
\text { culturing }\end{array}$ \\
\hline$\overline{\text { Oral }}$ & $\mathrm{V}$ & $\mathrm{N} / \mathrm{A}$ & $\mathrm{N} / \mathrm{A}$ & $\mathrm{N} / \mathrm{A}$ & $\mathrm{N} / \mathrm{A}$ & $8(6) / 14$ & $1 / 10$ & $\mathrm{~N} / \mathrm{A}$ & $\mathrm{N} / \mathrm{A}$ \\
\hline trial & $\mathrm{V}$ and $\mathrm{C}^{\mathrm{e}}$ & 5 & 5 & $\mathrm{~N} / \mathrm{A}$ & 100 & $20(14) / 35^{f}$ & $2 / 25$ & $20(10) / 33$ & $0 / 33$ \\
\hline & $\mathrm{C}$ & 4 & $0 *$ & 72 & 0 & $0 / 28 * *$ & $0 / 20$ & $10(0) / 10 * * *$ & $8 / 10 * *$ \\
\hline IM & $\mathrm{V}$ and $\mathrm{C}$ & 4 & 4 & $\mathrm{~N} / \mathrm{A}$ & 100 & $0 / 48^{\mathrm{f}}$ & $1 / 40$ & $23(9) / 40$ & $0 / 40$ \\
\hline trial & $\mathrm{C}$ & 4 & $0^{*}$ & 84 & 0 & $0 / 48$ & $0 / 40$ & $12(0) / 12 * *$ & $9 / 12 * * *$ \\
\hline
\end{tabular}

${ }^{a} \mathrm{~V}$ : vaccine control group; $\mathrm{V}$ and $\mathrm{C}$ : vaccine-and-challenge group; $\mathrm{C}$ : challenge control group.

${ }^{\mathrm{b}}$ For ethical reasons, the time period from challenge infection to euthanasia due to critical illness was used in the calculation of the mean time until death.

c Number of cultures positive for Salmonella (the vaccine strain (pre-challenge) and the challenge strain (postchallenge)) over the total number of samples tested in each group. Isolation was performed using both the direct and enrichment isolation methods. Numbers in parentheses indicate the number of positive results detectable only by using the enrichment isolation method.

d Number of cultures positive for Salmonella (the vaccine strain (pre-challenge) and the challenge strain (postchallenge)) over the total number of samples tested in each group.

e One calf that was euthanized before challenge due to pneumonia caused by Pasteurella multocida infection is not reported in this table. Two of the five calves were scheduled for euthanasia four days PC to compare the distribution and persistence of the vaccine and challenge strains in the body with calves in the challenge control group.

${ }^{\mathrm{f}}$ Frequency of isolation of the vaccine strain between the two groups was significantly different $(p<0.0001$ by two-sided Fisher's exact test).

In the oral trial, $* p=0.0079 ; * * p<0.0001$ and $* * * p=0.0196$ (two-tailed Fisher's exact test) when compared with the vaccine-and-challenge group. In the IM trial, $* p=0.0286 ; * * p=0.0049$ and $* * * p<0.0001$ (two-sided Fisher's exact test) when compared with the vaccine-and-challenge group. 
Table II. Frequency of clinical signs in calves monitored over a ten-day observation period posthomologous challenge infection.

\begin{tabular}{|c|c|c|c|c|c|c|c|c|}
\hline \multirow[t]{2}{*}{ Trial } & \multirow[t]{2}{*}{ Group $^{a}$} & \multicolumn{7}{|c|}{ Clinical signs } \\
\hline & & $\begin{array}{l}\text { Decrease } \\
\text { in appetite }\end{array}$ & $\begin{array}{l}\text { Temperature } \\
\text { rise }^{\mathrm{b}} \text { or drop } \\
\text { to lower than } \\
\text { usual after } \\
\text { peak }^{\mathrm{c}}\end{array}$ & $\begin{array}{l}\text { Increase } \\
\text { in heart } \\
\text { rate }^{\mathrm{d}}\end{array}$ & $\begin{array}{l}\text { Increase } \\
\text { in } \\
\text { respiration } \\
\text { rate }^{\mathrm{d}}\end{array}$ & $\begin{array}{l}\text { Dehydration } \\
\quad(>7 \%)^{\mathrm{e}}\end{array}$ & $\begin{array}{l}\text { Depression }^{\mathrm{f}} \\
\text { and/or } \\
\text { recumbency }\end{array}$ & Total \\
\hline \multirow[t]{3}{*}{ Oral trial } & $\begin{array}{l}\mathrm{V} \text { and } \mathrm{C} \\
(n=5)^{\mathrm{g}}\end{array}$ & $1 / 73^{i}$ & $26 / 73$ & $5 / 73$ & $0 / 73$ & $3 / 73$ & $24 / 73$ & $59 / 438$ \\
\hline & $\begin{array}{c}\mathrm{C} \\
(n=4)^{\mathrm{h}}\end{array}$ & $11 / 27$ & $19 / 27$ & $3 / 27$ & $15 / 27$ & $2 / 27$ & $19 / 27$ & $69 / 162$ \\
\hline & $p$ value $\mathrm{e}^{\mathrm{j}}$ & $<0.0001$ & $=0.0029$ & NS & $<0.0001$ & NS & $=0.0012$ & $<0.0001$ \\
\hline \multirow[t]{3}{*}{ IM trial } & $\begin{array}{l}V \text { and C } \\
(n=4)\end{array}$ & $0 / 80$ & $27 / 80$ & $11 / 80$ & $2 / 80$ & $0 / 80$ & $8 / 80$ & $48 / 480$ \\
\hline & $\begin{array}{c}\mathrm{C} \\
(n=4)^{\mathrm{h}}\end{array}$ & $7 / 32$ & $20 / 32$ & $10 / 32$ & $11 / 32$ & $0 / 32$ & $15 / 32$ & $63 / 192$ \\
\hline & $p$ value $^{\mathrm{j}}$ & $<0.0001$ & $=0.0064$ & NS & $<0.0001$ & NS & $<0.0001$ & $<0.0001$ \\
\hline
\end{tabular}

Clinical signs were monitored twice a day (7:00 am and 4:00 pm).

${ }^{\mathrm{a}} \mathrm{V}$ and $\mathrm{C}$ : vaccine-and-challenge group; $\mathrm{C}$ : challenge control group.

${ }^{\mathrm{b}}$ Equal to or higher than $40^{\circ} \mathrm{C}$.

${ }^{\mathrm{c}}$ More than $1{ }^{\circ} \mathrm{C}$ lower than the average pre-challenge (between day 6 and day 12) body temperature of each calf.

${ }^{\mathrm{d}}$ Increase of more than $30 \%$ of the average pre-challenge (between day 6 and day 12) rate of each calf.

${ }^{\mathrm{e}}$ The skin over the scapula persists for $>2$ seconds in the skinfold test, and clear signs of enophthalmos.

${ }^{\mathrm{f}}$ Responsive to environmental stimuli but unwilling to perform normally.

${ }^{\mathrm{g}}$ One calf that was euthanized before challenge due to pneumonia caused by Pasteurella multocida infection is not reported in this table. Two of the five calves were scheduled for euthanasia four days PC to compare the distribution and persistence of the vaccine and challenge strains in the body with calves in the challenge control group.

${ }^{\mathrm{h}}$ Calves in the challenge control groups were euthanized within four days PC due to severe septicaemic salmonellosis.

${ }^{i}$ The number of observations at which calves showed clinical signs over the total number of observations.

j Statistical analyses were carried out using two-sided Fisher's exact test to compare the results of two groups in each trial.

NS: not significant.

all challenged calves in both the oral and IM vaccine trials. The challenge strain was then isolated from the vaccinated calves in the oral and IM trials only following enrichment for up to eight days and up to 11 days PC, respectively. The number of Salmonella in the faeces of the challenge controls remained at a high level, approximately $10^{5}-10^{8} \mathrm{cfu} / \mathrm{g}$ in both the oral and IM trials, or gradually increased until the calves died or were euthanized. In the oral vaccine trial, all ten faecal specimens collected from the challenge control group during the PC period were positive for the challenge strain, as compared to 20 out of 33 for the vaccine-and-challenge group $(p=0.0196)$.
Similarly, all 12 faecal specimens collected from the challenge control group in the IM vaccine trial during the same period were positive for the challenge strain, as compared to 23 out of 40 for the vaccine-and-challenge group ( $p=0.0049)$ (Tab. I).

\subsubsection{Isolation of Salmonella from blood}

During the post-vaccination and prechallenge period, the vaccine strain was isolated on one occasion only from three of the seven orally vaccinated calves (the calf euthanized on day 8 due to pasteurellosis was not included). In the IM vaccine trial, the 
vaccine strain was not isolated throughout the observation period, except on a single occasion post-booster vaccination (PBV) in the vaccine-and-challenge group. In both oral and IM vaccine trials Salmonella were never isolated from the blood of vaccinated calves following challenge infection. In contrast, the challenge strain was repeatedly isolated from non-vaccinated animals throughout the observation period until death or euthanasia (Tab. I).

\subsubsection{Isolation of Salmonella from tissues and intestinal contents}

In the oral trial, low numbers of the vaccine strain (approximately $10^{2} \mathrm{cfu} / \mathrm{g}$ ) were isolated from the liver, spleen, MLN and ileocaecal and colonic contents of the calf euthanized due to pasteurellosis eight days PV (Tab. III). In the IM trial, small numbers (approximately $10^{1} \mathrm{cfu} / \mathrm{g}$ or less) of the vaccine strain were isolated only from the liver and spleen of two calves which were euthanized six days PV and five days PBV, respectively (Tab. IV).

Following challenge infection in both oral and IM trials, the challenge strain was isolated from most tested sites of the challenge control calves that had died or were euthanized due to severe salmonellosis (Tabs. III and IV). In the oral trial, the challenge strain was isolated only from the intestinal contents and MLN of two calves in the vaccine-and-challenge group that were experimentally sacrificed four days PC. Salmonella were not isolated from any tissue or intestinal content specimens of the remaining calves that survived the trial and were euthanized 18 days PC. Salmonella were not isolated from any tissue or intestinal content specimens of the two calves in the vaccine control group which were euthanized 40 days PV (Tab. III). In the IM trial, the challenge bacteria were not isolated from any specimens collected from vaccinated calves 18 days PC with the exception of a single MLN sample and only following enrichment (Tab. IV).

\subsection{Heterologous vaccine trial}

\subsubsection{Clinical appearance}

Following vaccination, no calves in the oral and IM vaccine groups showed clinical signs.
No clinical signs appeared following booster vaccination either, except soft stools in four out of seven orally vaccinated calves, and mild swelling of the injection site in a few calves vaccinated via the IM route.

Following challenge infection, none of the calves showed severe clinical signs requiring euthanasia and survived throughout the 15day PC observation period. However, the frequency of total clinical signs of calves in the challenge control group during this period was significantly higher than calves in the oral $(p=0.0412)$ and the IM $(p=0.004)$ vaccine groups (Tab. V). The only clinical signs in both the oral and IM vaccine groups were transient fever and diarrhoea. In the challenge control group, one calf showed clinical signs of loss of appetite, depression, diarrhoea (often with mucus and blood) and fever for several days PC, and some other calves had a fever and diarrhoea.

\subsubsection{Isolation of Salmonella from faeces}

In the oral vaccine group, N-RM25 was isolated from five specimens (three by the DI method and two by the EI method only) over the two days immediately following vaccination, and from one specimen using enrichment on the day following booster. The strain was not isolated from the IM vaccine group or the challenge control group during the pre-challenge period. The frequency of faecal shedding of the vaccine strain in the oral vaccine group during this period was significantly higher than the IM vaccine and the challenge control groups $(p=0.028)$ (Tab. V).

Following challenge infection, the challenge strain was isolated from faecal samples in all groups. By using the DI method, only two of the total number of 98 specimens collected from each vaccine group during this period were positive for the challenge strain, as compared to 13 for the challenge control group ( $p=0.0054)$. However, when using the EI method, 55 of the collected specimens from the IM vaccine group were positive for the strain, as compared to 76 for the oral vaccine group ( $p=0.0023$ ), and 80 for the challenge 
Table III. Distribution of Salmonella upon postmortem examination of calves in the oral vaccine trial followed by homologous challenge infection.

\begin{tabular}{|c|c|c|c|c|c|c|c|c|c|c|}
\hline \multirow[t]{2}{*}{ Group } & \multirow{2}{*}{$\begin{array}{c}\text { Day post- } \\
\text { vaccination }\end{array}$} & \multicolumn{9}{|c|}{ Organs, tissues, and contents } \\
\hline & & IC (cfu/g) & CAC (cfu/g) & $\mathrm{CC}(\mathrm{cfu} / \mathrm{g})$ & Liver (cfu/g) & Spleen (cfu/g) & Bile (cfu/g) & Lung $^{\mathrm{a}}$ & Kidney $^{\mathrm{a}}$ & $\mathrm{MLN}^{\mathrm{a}}$ \\
\hline \multirow{6}{*}{$\begin{array}{l}\text { Vaccine } \\
\text { and } \\
\text { challenge }\end{array}$} & $8^{\mathrm{b}}$ & $3 \times 10^{2} \mathrm{R}$ & $\mathrm{N} / \mathrm{A}$ & $1 \times 10^{2} \mathrm{R}$ & $6 \times 10^{2} \mathrm{R}$ & $2 \times 10^{2} \mathrm{R}$ & - & Pasteurella & - & $+\mathrm{R}$ \\
\hline & $18^{\mathrm{c}}$ & $8 \times 10^{6} \mathrm{~S}$ & $\mathrm{~N} / \mathrm{A}$ & $2 \times 10^{6} \mathrm{~S}$ & - & - & - & - & - & $+\mathrm{S}$ \\
\hline & $18^{\mathrm{c}}$ & $3 \times 10^{6} \mathrm{~S}$ & N/A & $2 \times 10^{5} \mathrm{~S}$ & - & - & - & - & - & $+\mathrm{S}$ \\
\hline & 32 & - & $\mathrm{N} / \mathrm{A}$ & - & - & - & - & - & - & - \\
\hline & 32 & - & $\mathrm{N} / \mathrm{A}$ & - & - & - & - & - & - & - \\
\hline & 32 & - & $\mathrm{N} / \mathrm{A}$ & - & - & - & - & - & - & - \\
\hline \multirow{4}{*}{$\begin{array}{l}\text { Challenge } \\
\text { control }\end{array}$} & 16 & $3 \times 10^{7} \mathrm{~S}$ & $\mathrm{~N} / \mathrm{A}$ & $1 \times 10^{7} \mathrm{~S}$ & $1 \times 10^{4} \mathrm{~S}$ & $2 \times 10^{5} \mathrm{~S}$ & - & $+\mathrm{S}$ & $+\mathrm{S}$ & $+\mathrm{S}$ \\
\hline & $17^{\mathrm{d}}$ & $+\mathrm{S}$ & $\mathrm{N} / \mathrm{A}$ & $+\mathrm{S}$ & $+\mathrm{S}$ & $+\mathrm{S}$ & $+\mathrm{S}$ & $+\mathrm{S}$ & $+\mathrm{S}$ & $+\mathrm{S}$ \\
\hline & 18 & $5 \times 10^{4} \mathrm{~S}$ & $\mathrm{~N} / \mathrm{A}$ & $2 \times 10^{5} \mathrm{~S}$ & $2 \times 10^{3} \mathrm{~s}$ & $2 \times 10^{3} \mathrm{~S}$ & - & - & $+\mathrm{S}$ & $+\mathrm{S}$ \\
\hline & 18 & $2 \times 10^{7} S$ & $\mathrm{~N} / \mathrm{A}$ & $4 \times 10^{6} \mathrm{~S}$ & $9 \times 10^{4} \mathrm{~S}$ & $1 \times 10^{4} \mathrm{~S}$ & $5 \times 10^{7} S$ & $+\mathrm{S}$ & $+\mathrm{S}$ & $+\mathrm{S}$ \\
\hline \multirow{2}{*}{$\begin{array}{l}\text { Vaccine } \\
\text { control }\end{array}$} & 40 & - & N/A & - & - & - & - & - & - & - \\
\hline & 40 & - & N/A & - & - & - & - & - & - & - \\
\hline
\end{tabular}

Day 0: vaccination with $S$. Dublin N-RM25; day 14: challenge infection with $S$. Dublin wild strain FD436. IC: ileal contents; CAC: caecal contents; CC: colonic contents; MLN: mesenteric lymph node; +: positive for Salmonella isolation; -: negative for Salmonella isolation; R: nalidixic acid and rifampicin resistant strain (N-RM25); S: nalidixic acid and rifampicin sensitive strain (FD436).

a Quantitative investigation was not performed.

${ }^{\mathrm{b}}$ Euthanized due to severe signs of pneumonia caused by Pasteurella multocida

${ }^{c}$ Experimentally euthanized to compare the distribution of Salmonella in the body with calves in the challenge control group.

${ }^{\mathrm{d}}$ Quantitative investigation was not performed as the calf was found dead before performing euthanasia. 
Table IV. Distribution of Salmonella upon postmortem examination of calves in the intramuscular vaccine trial followed by homologous challenge infection.

\begin{tabular}{|c|c|c|c|c|c|c|c|c|c|c|}
\hline \multirow{2}{*}{ Group } & \multirow{2}{*}{$\begin{array}{c}\text { Day post- } \\
\text { vaccination }\end{array}$} & \multicolumn{9}{|c|}{ Organs, tissues, and contents } \\
\hline & & $\mathrm{IC}(\mathrm{cfu} / \mathrm{g})$ & $\mathrm{CAC}(\mathrm{cfu} / \mathrm{g})$ & $\mathrm{CC}(\mathrm{cfu} / \mathrm{g})$ & Liver $(\mathrm{cfu} / \mathrm{g})$ & Spleen $(\mathrm{cfu} / \mathrm{g})$ & Bile (cfu/g) & Lung $^{\mathrm{a}}$ & Kidney $^{a}$ & $\mathrm{MLN}^{\mathrm{a}}$ \\
\hline \multirow{6}{*}{$\begin{array}{l}\text { Vaccine and } \\
\text { challenge }\end{array}$} & $6^{\mathrm{b}}$ & - & - & - & $1 \times 10 \mathrm{R}$ & $3 \times 10 \mathrm{R}$ & - & - & - & - \\
\hline & $18^{\mathrm{b}}$ & - & - & - & - & +ER & - & - & - & - \\
\hline & 38 & - & - & - & - & - & - & - & - & $+\mathrm{ES}$ \\
\hline & 38 & - & - & - & - & - & - & - & - & - \\
\hline & 38 & - & - & - & - & - & - & - & - & - \\
\hline & 38 & - & - & - & - & - & - & - & - & - \\
\hline \multirow[t]{4}{*}{ Challenge control } & 22 & $1 \times 10^{6} \mathrm{~S}$ & $5 \times 10^{6} \mathrm{~S}$ & $4 \times 10^{6} \mathrm{~S}$ & $2 \times 10^{5} \mathrm{~S}$ & $4 \times 10^{5} \mathrm{~S}$ & - & $+\mathrm{S}$ & $+\mathrm{ES}$ & $+\mathrm{S}$ \\
\hline & 23 & $2 \times 10^{9} \mathrm{~S}$ & $4 \times 10^{7} \mathrm{~S}$ & $4 \times 10^{8} \mathrm{~S}$ & $2 \times 10^{3} \mathrm{~S}$ & $1 \times 10^{3} \mathrm{~S}$ & - & $+\mathrm{S}$ & $+\mathrm{ES}$ & $+\mathrm{S}$ \\
\hline & 23 & $2 \times 10^{6} \mathrm{~S}$ & $3 \times 10^{4} \mathrm{~s}$ & $4 \times 10^{4} \mathrm{~S}$ & $2 \times 10^{3} \mathrm{~s}$ & $1 \times 10^{3} \mathrm{~s}$ & - & $+\mathrm{S}$ & $+\mathrm{ES}$ & $+\mathrm{S}$ \\
\hline & 24 & $4 \times 10^{8} \mathrm{~S}$ & $2 \times 10^{8} \mathrm{~S}$ & $3 \times 10^{8} \mathrm{~S}$ & $7 \times 10^{5} \mathrm{~S}$ & $1 \times 10^{6} \mathrm{~S}$ & - & $+\mathrm{S}$ & $+\mathrm{S}$ & $+\mathrm{S}$ \\
\hline \multicolumn{11}{|c|}{$\begin{array}{l}\text { Day 0: vaccination with } S \text {. Dublin N-RM25; day 13: booster vaccination with N-RM25; day } \\
\text { contents; CAC: caecal contents; CC: colonic contents; MLN: mesenteric lymph node; +: positi } \\
\text { nalidixic acid and rifampicin resistant strain (N-RM25); S: nalidixic acid and rifampicin sensit } \\
\text { enrichment method. } \\
\text { a Quantitative investigation was not performed. } \\
\text { b Experimentally euthanized to determine the distribution of Salmonella in the body. }\end{array}$} \\
\hline
\end{tabular}


Table V. Oral and intramuscular vaccine trials in calves using N-RM25 followed by heterologous challenge infection with a wild strain of $S$. Typhimurium DH436.

\begin{tabular}{lcccccc}
\hline Group & $\begin{array}{c}\text { No. of calves } \\
\text { surviving post- } \\
\text { challenge }^{\mathrm{a}}\end{array}$ & $\begin{array}{c}\text { Frequency of } \\
\text { clinical signs } \\
\text { post-challenge }\end{array}$ & $\begin{array}{c}\text { Pre-challenge } \\
\text { faecal } \\
\text { culturing }\end{array}$ & $\begin{array}{c}\text { Pre-challenge } \\
\text { blood } \\
\text { culturing }\end{array}$ & $\begin{array}{c}\text { Post-challenge } \\
\text { faecal } \\
\text { culturing }^{\mathrm{d}}\end{array}$ & $\begin{array}{c}\text { Post-challenge } \\
\text { blood } \\
\text { culturing }\end{array}$ \\
\hline $\begin{array}{l}\text { Oral vaccine } \\
\text { and challenge }\end{array}$ & $7 / 7$ & $7 / 630^{*}$ & $6(3) / 70$ & $0 / 35$ & $76(74) / 98^{*}$ & $0 / 70$ \\
$\begin{array}{l}\text { IM vaccine } \\
\text { and challenge }\end{array}$ & $7 / 7$ & $4 / 630^{* *}$ & $0 / 70^{*}$ & $0 / 35$ & $55(53) / 98^{* *}$ & $0 / 70$ \\
$\begin{array}{l}\text { Challenge } \\
\text { control }\end{array}$ & $7 / 7$ & $18 / 630$ & $0 / 70^{*}$ & $0 / 35$ & $80(67) / 98$ & $0 / 70$ \\
\hline
\end{tabular}

${ }^{a}$ Number of surviving calves over the total number of calves in each group.

${ }^{\mathrm{b}}$ Six parameters of clinical signs (appetite, body temperature, heart rate, faecal consistency, hydration and general appearance) were monitored for 15 days PC $* p=0.0412 ; * * p=0.004$ (two-tailed Fisher's exact test) when compared with the control group.

${ }^{c}$ Number of cultures positive for Salmonella (the vaccine strain) over the total number of samples tested in each group during the post-vaccination and pre-challenge period. Numbers in parentheses indicate the number of positive results detectable only by using the enrichment isolation method. $* p=0.028$ (two-tailed Fisher's exact test) when compared with the oral vaccine group.

${ }^{\mathrm{d}}$ Number of cultures positive for Salmonella (the challenge strain) over the total number of samples tested in each group during the post-challenge period. Numbers in parentheses indicate the number of positive results detectable only by using the enrichment isolation method. $* p=0.0054$ when compared with the number of positive isolations from the challenge control group using the direct isolation method; $* * p=0.0054$ when compared with the number of positive isolations from the challenge control group using the direct isolation method, and $p=0.0023$ and $p=0.0002$ when compared with the number of positive isolations using the enrichment isolation method from the oral vaccine and the challenge control groups, respectively (two-tailed Fisher's exact test).

control group ( $p=0.0002)$ (Tab. V). Because the challenge strain was only isolated following enrichment in most cases, a comparison of the number of viable bacteria in the faecal samples was not made.

\subsubsection{Isolation of Salmonella from blood, tissues, and intestinal contents}

Salmonella were not isolated from the blood, internal organs, and bile of calves in any group. The challenge strain was isolated from MLN of six out of the seven calves in the oral vaccine group and all seven calves in the challenge control group. In contrast, the MLN of only three calves in the IM vaccine group were positive for the strain (Tabs. V and VI).

Twenty-one of the total number of 28 intestinal content specimens collected from the challenge control group were positive for the challenge strain, as compared to five for the oral vaccine group ( $p<0.0001)$ and 12 for the IM vaccine group $(p=0.0288)$ but there was no significant difference between these two vaccine groups (Tab. VI).

\section{DISCUSSION}

The study described in this paper is one of a series planned to assess N-RM25 as a potential live attenuated vaccine for use in cattle. It was designed to investigate safety and efficacy of N-RM25 in animals in a particular age group ( $\leq 6$ weeks old) because these animals are the most susceptible to both $S$. Dublin and $S$. Typhimurium infection [52, 54]. In addition, salmonellosis in adult cattle caused by $S$. Dublin often results from the reactivation of infection in prolonged latent carriers due to various types of stress rather than being a direct result of recently acquired infection [35, 54]. Therefore, the protection of young calves

Page 10 of 16 (page number not for citation purpose) 
Table VI. Number of mesenteric lymph node and intestinal content specimens that were positive for the challenge strain $S$. Typhimurium DH436 upon postmortem examination of calves in the heterologous vaccine trial.

\begin{tabular}{lcccccc}
\hline Group & MLN & IC & CAC & CC & RC & $\begin{array}{c}\text { Total number of } \\
\text { Salmonella positive } \\
\text { intestinal contents }\end{array}$ \\
\hline $\begin{array}{l}\text { Oral vaccine and challenge } \\
(n=7)\end{array}$ & 6 & $1(1)$ & $1(1)$ & $1(1)$ & $2(2)$ & $5(5) / 28^{*}$ \\
$\begin{array}{l}\text { IM vaccine and challenge } \\
(n=7)\end{array}$ & 3 & $1(1)$ & $4(4)$ & $4(4)$ & $3(3)$ & $12(12) / 28^{* *}$ \\
$\begin{array}{l}\text { Challenge control } \\
(n=7)\end{array}$ & 7 & $4(4)$ & $5(4)$ & $5(3)$ & $7(7)$ & $21(18) / 28$ \\
\hline
\end{tabular}

Day 0: vaccination with $S$. Dublin N-RM25; day 14: booster vaccination with N-RM25; days 28 and 36: challenge infection with $S$. Typhimurium wild strain DH436; day 43: postmortem examinations. MLN: mesenteric lymph node; IC: ileal contents; CAC: caecal contents; CC: colonic contents; RC: rectal contents. Numbers in parentheses indicate the number of positive results detectable only by using the enrichment isolation method. $* p<0.0001$; $* * p=0.0288$ (two-tailed Fisher's exact test) when compared with the challenge control group.

from infection is an important prophylactic measure, not only for maintaining the health of calves but also for reducing the number of carrier animals in the herd. The World Organization for Animal Health also states that evaluation of efficacy of a veterinary vaccine should be carried out using the youngest, most susceptible animals for which the vaccine is to be recommended [51].

Single or double vaccination of calves at two weeks of age via the oral route with doses of approximately $10^{9}$ to $10^{10} \mathrm{cfu} /$ animal, and double vaccination via the IM route using a dose of $10^{8}$ to $10^{9} \mathrm{cfu} /$ animal were safe with few associated side effects. Some vaccinated calves produced transient fever and some mild local reactions only following booster vaccination in the homologous IM vaccine trial. Endotoxins of gram-negative bacteria are believed to induce local and systemic inflammatory reactions $[20,53]$. In the homologous trial, the vaccine strain was washed in PBS once following harvest from SBA medium plates. However, in the heterologous IM vaccine trial, the vaccine strain was washed three times in PBS and this greatly reduced inflammatory reactions following booster vaccination.

The oral vaccination route is considered to be the most promising antigen delivery method in terms of directly stimulating mucosal immunity in the gut $[14,24]$. Potential contamination of the environment through faecal shedding of vaccine organisms following oral vaccination, however, is a common problem, particularly when GMO are used as vaccine strains $[28,29,40]$. In this study, administration with $\mathrm{N}-\mathrm{RM} 25$ via the IM route was more advantageous than via the oral route because of reduced shedding of the vaccine strain in faeces. Although the period of shedding was short ( $\leq 8$ days) when N-RM25 was administered by the oral route in both homologous and heterologous trials, it was still significant when compared with calves vaccinated via the IM route.

In the homologous trials, a scheduled euthanasia was performed for some of the vaccinated calves to investigate the distribution of the vaccine strain in the host. Following oral and IM vaccination, N-RM25 was isolated in low numbers from the liver and spleen of calves euthanized during the postvaccination pre-challenge period. The strain was also isolated from the MLN following oral vaccination. These results suggest that, in vivo, N-RM25 may survive in macrophages, which would most likely carry the organism from the inoculation site to these remote sites [6]. However, the vaccine strain was not isolated from any specimens collected at 18 days following oral vaccination and 25 days following IM booster vaccination, confirming 
that colonisation by the vaccine strain was transitory, a desirable property for a live attenuated vaccine.

N-RM25 administered by either the oral or IM route significantly reduced the number of clinical signs and sufficiently protected calves against lethal homologous challenge infection. The results of bacterial culture from blood and tissue specimens collected from vaccinated calves strongly suggest that, irrespective of the administration route, the vaccine strain $\mathrm{N}$ RM25 prevents the development of systemic salmonellosis caused by $S$. Dublin. In heterologous trials, the vaccine also produced some protection against challenge with wild virulent $S$. Typhimurium DH436, significantly reducing the frequency of clinical signs and faecal shedding of the challenge strain. It has been suggested that early onset immunity which includes protective factors, such as competitive exclusion $[11,12]$, enhanced non-specific phagocytosis mediated mainly by activated macrophages and subsequent secretion of particular cytokines, such as interleukin 12 and interferon- $\gamma[21,26,30,48]$, is the major defence mechanism in the most susceptible age group of calves against Salmonella until acquired immunity is established [26]. Although competitive exclusion is effective in protecting animals in the very early stages of life $[11,12,55]$, oral administration, not parenteral administration, of a live vaccine is usually required as the vaccine strains compete with the challenge strains for ecological niches within the gut. Interestingly however, in the heterologous vaccine trial in this study, IM vaccination significantly reduced faecal shedding of the challenge strain, and prevented colonisation of MLN more effectively than vaccination via the oral route. In the homologous vaccine trial, there were no significant differences in the reduction and elimination of the challenge strain from the host between oral and IM vaccination. Although N-RM25 administered orally probably stimulated some level of immunity, as penetration of the MLN by the organism following oral vaccination was confirmed, the above results suggest that $\mathrm{N}-\mathrm{RM} 25$ vaccine administered by the IM route induces better early onset protection in the host than the oral route. One possible reason for this is the difference between oral and IM vaccination in the type of antigen presenting cells at the vaccine inoculation sites. When vaccine antigens are administered intramuscularly, some slight tissue damage occurs at the site, followed by inflammatory infiltration by phagocytic cells, such as neutrophils and macrophages. Thus, it is mainly macrophages that take up, process, and eventually present the antigens to initiate immune responses [41]. In contrast, following vaccination using the oral route, vaccine antigens are likely to be taken up by dendritic cells, rather than macrophages, at antigen sampling sites such as follicle-associated epithelium (FAE) and $\mathrm{M}$ cells, because the tissue region facing these sites is densely packed with dendritic cells and B lymphocytes, but few macrophages $[19,36,38]$. Because the mechanism by which macrophages process and present antigens is quite different from that of dendritic cells $[9,18,37]$, they may initiate different types and levels of immune response, an important issue for vaccine delivery.

In addition, calves vaccinated orally and those vaccinated intramuscularly produced intestinal signs which were markedly different from those produced by non-vaccinated calves following homologous lethal challenge infection. All vaccinated calves, irrespective of the vaccination route, developed profuse watery diarrhoea, whereas non-vaccinated controls produced only a small amount of diarrhoea often containing mucus and blood. These results suggest that some factors, possibly mucosal immunity, contribute to the development of inflammatory reactions at the site. It was previously shown in a trial using mice that N-RM25 administered via the parenteral route induced significant mucosal immune responses in the gut 14 days post vaccination [27].

Some virulence factors of Salmonella, such as the invasion-associated type III secretion system and effector proteins, including Salmonella outer proteins (Sops), appear to play an important role in invasion, induction of inflammation, and fluid production at the site of infection [17,44,50,56]. However, although 
some mechanisms of the host, such as the gastrointestinal mucosal barrier, are suggested to play an important role in host-pathogen interaction [1], it is still unclear how interaction between immunity and Salmonella at the site affect the induction of these inflammatory reactions. Furthermore, as the structure and components of the mucosal immune system in the gut of young animals differ from those of adult animals [5, 22], host-pathogen interaction and subsequent clinical signs may vary greatly depending on the level of maturity of this immune system. The mechanisms involved in immunity in the most susceptible age group of calves may be very complex. Therefore, it remains to be determined whether $\mathrm{N}-\mathrm{RM} 25$ also induces mucosal immunity in calves following IM administration as well as following oral inoculation, as previously shown in mice, and whether additional defence mechanisms induced by N-RM 25 contribute to reduced faecal shedding of the Salmonella challenge strain. In addition, challenge infection was carried out within two weeks postimmunisation in this study to investigate the early onset protective properties of N-RM25. This type of protection is often attributed to Tcell independent immunity. Because immunologic memory is not involved in this type of immunity, it usually confers only short-term protection $[16,26]$. However, in a previous homologous vaccine trial in mice, N-RM25 administered once by the intraperitoneal route produced a high level of protection against lethal challenge infection conducted five weeks post vaccination ${ }^{2}$. This may be evidence that N-RM25 also stimulates late onset protective immunity to $S$. Dublin, but this needs to be investigated in the natural host.

It is difficult to compare the early onset protective properties of N-RM25 with other Salmonella live attenuated vaccine candidates in other trials because different methods, particularly different challenge strains and doses, were used in each trial. In one homologous vaccine trial, calves were orally vaccinated

\footnotetext{
${ }^{2}$ Mizuno T., The development of a live attenuated Salmonella Dublin vaccine, Doctor of Philosophy thesis, St. Lucia, QLD, Australia, 2003.
}

twice using an aro $^{-}$mutant of $S$. Dublin and challenged via the oral route two weeks following immunisation [40]. The challenge strain was isolated from the faeces of some control (non-vaccinated) animals only using an enrichment cultivation method following challenge infection, suggesting that only a small number of viable challenge strain organisms actually reached the intestine. Despite this, the vaccine failed to prevent penetration of major internal organs by the challenge strain and at least three vaccinations at very high doses $\left(5 \times 10^{11} \mathrm{cfu} / \mathrm{calf}\right)$ were required to obtain significant protection. Because one of the goals of vaccination against Salmonella is to prevent the establishment of a carrier state, the ability of a vaccine to prevent penetration of deeper tissue sites, such as the liver, spleen, and gall bladder by the organisms, is an important consideration. In the present homologous trial, probably due to the effect of the buffer administered with the challenge strain, approximately $10^{6}-10^{7} \mathrm{cfu} / \mathrm{g}$ of viable challenge bacteria were isolated from the faeces of all challenged calves in both vaccinated and non-vaccinated groups on the day following challenge infection, strongly suggesting that high numbers of viable challenge bacteria reached sites where infection occurs. Although all non-vaccinated controls had died or were euthanized within four days PC due to severe systemic salmonellosis, the N-RM25 vaccine, irrespective of administration route, prevented the development of systemic infection, effectively eliminated the challenge strain organisms and protected calves from lethal challenge infection.

In conclusion, N-RM25, which is a nonGMO spontaneous mutant, was safe to use as a vaccine strain in calves up to six weeks of age. Both oral and IM vaccination with this strain produced protection against homologous and heterologous challenge infection. The IM vaccination route was safer than the oral route in terms of contamination of the environment by the vaccine strain. Most interestingly, administration of N-RM25 via the IM route was equally, or more efficient in controlling faecal shedding of $S$. Dublin and $S$. Typhimurium in young calves when compared to 
administration via the oral route. If N-RM25 administered by the IM route is shown to produce late onset protection in older animals via T-cell dependent immunity, and is safe and efficacious during pregnancy, it may become a very useful live attenuated vaccine for the control and prevention of salmonellosis in dairy cattle.

Acknowledgments. This work was supported by grants from Australian Commonwealth Biotechnology Inovation Funding (No. BIF03317), the University of Queensland Research and Development Funding, and HerdVac Pty Ltd. We are indebted to the Ruminant Immunology Research Group, Australian Animal Health Laboratory, Commonwealth Scientific and Industrial Research Organization, Australia, for assistance in the heterologous vaccine trial.

\section{REFERENCES}

[1] Acheson D.W., Luccioli S., Mucosal immune responses, Best Pract. Res. Clin. Gastroenterol. (2004) 18:387-404.

[2] Anderson R.J., House J.K., Smith B.P., Kinde H., Walker R.L., Vande Steeg B.J., Breitmeyer R.E., Epidemiologic and biological characteristics of salmonellosis in three dairy herds, J. Am. Vet. Med. Assoc. (2001) 219:310-322.

[3] Australian Salmonella Reference Centre, 2003 Annual Report, in: Davos D. (Ed.), Institute of Medical and Veterinary Science, Adelaide, 2003, pp. 7-12.

[4] Bagley R., Mayhew I., Clinical examination of the nervous system, in: Radostits O.M., Mayhew I.G., Houston D.M. (Eds.), Veterinary clinical examination and diagnosis, W.B. Saunders, London, 2000,pp.493-541.

[5] Bailey M., Haverson K., The postnatal development of the mucosal immune system and mucosal tolerance in domestic animals, Vet. Res. (2006) 37:443-453.

[6] Bäumler A.J., Tsolis R.M., Heffron F., Virulence mechanisms of Salmonella and their genetic basis, in: Wray C., Wray A. (Eds.), Salmonella in domestic animals, CABI Publishing, New York, USA, 2000, pp. 57-72.

[7] Bowersock T.L., HogenEsch H., Suckow M., Guimond P., Martin S., Borie D., Torregrosa S., Park H., Park K., Oral vaccination of animals with antigens encapsulated in alginate microspheres, Vaccine (1999) 17:1804-1811.

[8] Davison H.C., Smith R.P., Pascoe S.J., Sayers A.R., Davies R.H., Weaver J.P., Kidd S.A., Dalziel R.W., Evans S.J., Prevalence, incidence and geographical

Page 14 of 16 (page number not for citation purpose) distribution of serovars of Salmonella on dairy farms in England and Wales, Vet. Rec. (2005) 157:703-711.

[9] De Jong J.M., Schuurhuis D.H., Ioan-Facsinay A., Welling M.M., Campus M.G., van der Voort E.I., Huizinga T.W., Ossendorp F., Verbeek J.S., Toes R.E., Dendritic cells, but not macrophages or B cells, activate major histocompatibility complex class II-restricted CD4+ $\mathrm{T}$ cells upon immune-complex uptake in vivo, Immunology (2006) 119:499-506.

[10] DesBordes C.K., Welch J.G., Influence of specific gravity on rumination and passage of indigestible particles, J. Anim. Sci. (1984) 59:470-475.

[11] Dueger E.L., House J.K., Heithoff D.M., Mahan M.J., Salmonella DNA adenine methylase mutants prevent colonization of newly hatched chickens by homologous and heterologous serovars, Int. J. Food Microbiol. (2003) 80:153-159.

[12] Dueger E.L., House J.K., Heithoff D.M., Mahan M.J., Salmonella DNA adenine methylase mutants elicit early and late onset protective immune responses in calves, Vaccine (2003) 21:3249-3258.

[13] Gay C.C., Radostits O.M., Clinical examination of the cardiovascular system, in: Radostits O.M., Mayhew I.G., Houston D.M. (Eds.), Veterinary clinical examination and diagnosis, W.B. Saunders, London, UK, 2000, pp. 245-291.

[14] Gerdts V., Mutwiri G.K., Tikoo S.K., Babiuk L.A., Mucosal delivery of vaccines in domestic animals, Vet. Res. (2006) 37:487-510.

[15] Guerin M.T., Martin S.W., Darlington G.A., Rajic A., A temporal study of Salmonella serovars in animals in Alberta between 1990 and 2001, Can. J. Vet. Res. (2005) 69:88-99.

[16] House J.K., Ontiveros M.M., Blackmer N.M., Dueger E.L., Fitchhorn J.B., McArthur G.R., Smith B.P., Evaluation of an autogenous Salmonella bacterin and a modified live Salmonella serotype Choleraesuis vaccine on a commercial dairy farm, Am. J. Vet. Res. (2001) 62:1897-1902.

[17] Jones M.A., Wood M.W., Mullan P.B., Watson P.R., Wallis T.S., Galyov E.E., Secreted effector proteins of Salmonella Dublin act in concert to induce enteritis, Infect. Immun. (1998) 66:5799-5804.

[18] Kalupahana, R.S., Mastroeni P., Maskell D., Blacklaws B.A., Activation of murine dendritic cells and macrophages induced by Salmonella enterica serovar Typhimurium, Immunology (2005) 115:462-472.

[19] Kelsall B.L., Strober W., Distinct populations of dendritic cells are present in the subepithelial dome of T cell regions of the murine Peyer's patch, J. Exp. Med. (1996) 183:237-247.

[20] Khan S.A., Everest P., Servos S., Foxwell N., Zahringer U., Brade H., Rietschel E.T., Dougan G., 
Charles I.G., Maskell D.J., A lethal role for lipid A in Salmonella infection, Mol. Microbiol. (1998) 29:571-579.

[21] Kincy-Cain T., Clements J.D., Bost K.L., Endogenous and exogenous interleukin-12 augment the protective immune response in mice orally challenged with Salmonella Dublin, Infect. Immun. (1996) 64:1437-1440.

[22] Liebler-Tenorio E.M., Pabst R., MALT structure and function in farm animals, Vet. Res. (2006) $37: 257-280$.

[23] Lynch M., Painter J., Woodruff R., Braden C., Surveillance for foodborne-disease outbreaks - United States 1998-2002, MMWR Surveill. Summ. (2006) 55:1-42.

[24] Mastroeni P., Cahill B., Simmons C., Dougan G., Vaccines against gut pathogens, Gut (1999) 45:633-635.

[25] Miles A.A., Misra S.S., Irwin J.O., The estimation of the bactericidal power of the blood, J. Hyg. Camb. (1938) 38:732-749.

[26] Mittrücker H., Kaufmann S.H.E., Immune response to infection with Salmonella Typhimurium in mice, J. Leukoc. Biol. (2000) 67:457-463.

[27] Mizuno T., Ploeg R., Trott D., A new concept to stimulate mucosal as well as systemic immunity by parenteral vaccination as applied to the development of a live attenuated Salmonella enterica serovar Dublin vaccine, Vet. Res. (2007) 38:773-794.

[28] Mohler V.L., Heithoff D.M., Mahan M. J., Walker K.H., Hornitzky M.A., McConnell C.S., Shum L.W., House J.K., Cross-protective immunity in calves conferred by a DNA adenine methylase deficient Salmonella enterica serovar Typhimurium vaccine, Vaccine (2006) 24:1339-1345.

[29] Mukkur T.K.S., Walker K.H., Jones D., Wronski E., Love D.N., Immunizing efficacy of aromaticdependent Salmonella Dublin in mice and calves, Comp. Immunol. Microbiol. Infect. Dis. (1991) 14:243-256.

[30] Nauciel C., Espinasse-Maes F., Role of gamma interferon and tumor necrosis factor alpha in resistance to Salmonella Typhimurium infection, Infect. Immun. (1992) 60:450-454.

[31] Poppe C., Martin L., Muckle A., Archambault M., McEwen S., Weir E., Characterization of antimicrobial resistance of Salmonella Newport isolated from animals, the environment, and animal food products in Canada, Can. J. Vet. Res. (2006) 70:105-114.

[32] Quinn P.J., Carter M.E., Markey B.K., Carter G.R., Clinical veterinary microbiology, Mosby International, Philadelphia, USA, 1999.
[33] Ray K.A., Warnick L.D., Mitchell R.M., Kaneene J.B., Ruegg P.L., Wells S.J., Fossler C.P., Halbert L.W., May K., Prevalence of antimicrobial resistance among Salmonella on Midwest and Northeast USA dairy farms, Prev. Vet. Med. (2007) 79:204-223.

[34] Richardson A., Salmonella Dublin infection in cattle, Aust. Vet. J. (1974) 50:463-466.

[35] Richardson A., Salmonellosis in cattle, Vet. Rec. (1975) 96:329-331.

[36] Ruedl C., Rieser C., Bock G., Wick G., Wolf G., Phenotypic functional characterization of $\mathrm{CD} 11 \mathrm{c}^{+}$ dendritic cell population in mouse Peyer's patches, Eur. J. Immunol. (1996) 26:1801-1806.

[37] Savina A., Amigorena S., Phagocytosis and antigen presentation in dendritic cells, Immunol. Rev. (2007) 219:143-156.

[38] Sirard J., Niedergang F., Kraehenbuhl J., Live attenuated Salmonella: a paradigm of mucosal vaccines, Immunol. Rev. (1999) 171:5-26.

[39] Smith B.P., Salmonellosis, in: Reinhardt R.W. (Ed.), Large animal internal medicine, C.V. Mosby, St. Louis, USA, 1990, pp. 818-822.

[40] Smith B.P., Dilling G.W., Roden L.D., Stocker B.A., Vaccination of calves with orally administered aromatic-dependent Salmonella Dublin, Am. J. Vet. Res. (1993) 54:1249-1255.

[41] Tizard I.R., Immunology, Saunders College Publishing, Philadelphia, USA, 1995.

[42] Todd E.C.D., Epidemiology of foodborne diseases: a worldwide review, World Health Stat. Q. (1997) 50:30-50.

[43] Trueman K.F., Thomas R.J., MacKenzie A.R., Eaves L.E., Duffy P.F., Salmonella Dublin infection in Queensland dairy cattle, Aust. Vet. J. (1996) 74:367-369.

[44] Tsolis R.M., Adams L.G., Ficht T.A., Bäumler A.J., Contribution of Salmonella Typhimurium virulence factors to diarrheal disease in calves, Infect. Immun. (1999) 67:4879-4885.

[45] Tyler J.W., Hancock D.D., Wiksie S.E., Holler S.L., Gay J.M., Gay C.C., Use of serum protein concentration to predict mortality in mixed-source dairy replacement heifers, J. Vet. Intern. Med. (1998) 12:79-83.

[46] USDA/APHIS/Veterinary Services, Prevalence of Salmonella spp. and Escherichia coli on US livestock operations, CO:USDA:APHIS:VS, Centers for Epidemiology and Animal Health, Fort Collins, 1999.

[47] Van Duijkeren E., Wannet W.J., Houwers D.J., van Pelt W., Serotype and phage type distribution of 
Salmonella strains isolated from humans, cattle, pigs, and chickens in the Netherlands from 1984 to 2001, J. Clin. Microbiol. (2002) 40:3980-3985.

[48] Vassiloyanakopoulos A.P., Okamoto S., Fierer J., The crucial role of polymorphonuclear leukocytes in resistance to Salmonella Dublin infections in genetically susceptible and resistant mice, Proc. Natl. Acad. Sci. USA (1998) 95:7676-7681.

[49] Wallis T.S., Paulin S.M., Plested J.S., Watson P.R., Jones P.W., The Salmonella Dublin virulence plasmid mediates systemic but not enteric phase of salmonellosis in cattle, Infect. Immun. (1995) 63:2755-2761.

[50] Watson P.R., Paulin S.M., Bland A.P., Jones P.W., Wallis T.S., Characterization of intestinal invasion by Salmonella Typhimurium and Salmonella Dublin and effect of a mutation in the $i n v H$ gene, Infect. Immun. (1995) 63:2743-2754.

[51] World Organization for Animal Health, Manual of diagnostic tests and vaccines for terrestrial animals, OIE, Paris, France, 2004, pp. 1018-1032.
[52] Wray C., Davies R.H., Salmonella infections in cattle, in: Wray C., Wray A. (Eds.), Salmonella in domestic animals, CABI Publishing, New York, USA, 2000, pp. 169-190.

[53] Wray C., McLaren I., Further studies on the use of Gal E mutants of Salmonella Typhimurium in calves: oral vaccination and toxicity studies, J. Vet. Med. B (1987) 34:22-29.

[54] Wray C., Sojka W.J., Review of the progress of dairy science: bovine salmonellosis, J. Dairy Res. (1977) 44:383-425.

[55] Zhang G., Ma L., Doyle M.P., Salmonellae reduction in poultry by competitive exclusion bacteria Lactobacillus salivarius and Streptococcus cristatus, J. Food Prot. (2007) 70:874-878.

[56] Zhang S., Santos R.L., Tsolis R.M., Stender S., Hardt W.D., Bäumler A.J., Adams L.G., The Salmonella enterica serotype Typhimurium effector proteins SipA, SopA, SopB, SopD, and SopE2 act in concert to induce diarrhea in calves, Infect. Immun. (2002) 70:3843-3855. 